\title{
Uma nova espécie de Orthoderella Giglio-Tos (Mantodea, Mantidae, Photinainae) do Brasil
}

\author{
Eliomar da Cruz Menezes ${ }^{1} \&$ Freddy Bravo ${ }^{1}$
}

${ }^{1}$ Laboratório de Sistemática de Insetos, LABIO, Departamento de Zoologia, Universidade Estadual de Feira de Santana, Avenida Transnordestina, S/N,
Bairro Novo Horizonte, 44036-900 Feira de Santana-BA, Brasil. mazinhomenezes@hotmail.com; freddy11bravo@yahoo.com.br

\begin{abstract}
A new species of Orthoderella Giglio-Tos (Mantodea, Mantidae, Photinainae) from Brazil. The Neotropical genus Orthoderella Giglio-Tos includes four species recorded in Argentina, Bolivia, Uruguay, and from central western, southern, and southeastern Brazil. Orthoderella caatingaensis sp. nov., from the Caatinga biome in northeastern Brazil, is described here. This new species can be recognized by having a black spot on the inner face of the fore coxae, which extends to its posterior external face; phalloid apophysis of the left dorsal phallomere trapezoidal in shape with the right margin sinuous and a laminate anterior process; and a ventral phallomere with a sclerotized and rugous distal process. An identification key, in both Portuguese and English, to the five species of Orthoderella is presented.
\end{abstract}

KEYWORDS. Bahia; Dictyoptera; Insecta; Neotropical region; taxonomy.

O gênero Orthoderella Giglio-Tos, 1897 está incluído em Photinainae, a subfamília mais rica de Mantidae nos neotrópicos, com 13 gêneros e 58 espécies conhecidas (Rivera 2010). Esta subfamília está amplamente distribuída na região Neotropical com registros desde o norte da América Central (Belize) até o sul da América do Sul, na Argentina (Agudelo et al. 2007).

Orthoderella foi criado para a espécie Orthoderella ornata Giglio-Tos, 1897 descrita da Bolívia (Giglio-Tos 1897) e conhecida, também, da Argentina e do Paraguai (Roy \& Stiewe 2011). Uma segunda espécie do gênero foi descrita 106 anos depois da espécie-tipo por Rivera (2003), Orthoderella deluchii Rivera, 2003, em florestas pluviais de altitude nos Andes orientais peruanos. Na revisão do gênero por Roy \& Stiewe (2011), duas novas espécies foram propostas, Orthoderella elongata Roy \& Stiewe, 2011 e Orthoderella brasiliensis Roy \& Stiewe, 2011, ambas com registros na Argentina, Uruguai e Brasil. O. elongata é conhecida no Brasil apenas na região Centro-Oeste (estado de Goiás), enquanto que $O$. brasiliensis é conhecida das regiões Centro-Oeste (estados de Goiás e Mato Grosso), Sudeste (estados de Minas Gerais e São Paulo) e Sul (estados de Santa Catarina e Rio Grande do Sul).

Neste trabalho é descrita a quinta espécie do gênero Orthoderella, sendo esta a primeira para a região da Caatinga, no nordeste do Brasil.

\section{MATERIAL E MÉTODOS}

Os exemplares de Orthoderella foram coletados com armadilha luminosa, armazenados em álcool $70 \%$ e posteriormente montados em alfinete entomológico. O abdômen de todos os exemplares foi recortado no oitavo segmento, colo- cado em ácido lático $85 \%$ por 15 minutos, de acordo com o método de Cumming (1992). A genitália foi separada dos segmentos terminais do abdômen e colocada em hidróxido de potássio $10 \%(\mathrm{KOH})$ a frio por 8 horas, lavada em água destilada por 10 minutos, submergida em ácido acético $10 \%$ por 10 minutos para neutralizar a ação do hidróxido de potássio e, imediatamente, transferido para álcool 70\%. Antes do estudo, a genitália foi corada com fucsina ácida $10 \%$ por 10 minutos, sendo depois armazenada em microtubo com glicerina e alfinetada junto ao espécime.

As fotos foram realizadas em estereomicroscópio Leica M205C acoplado a câmera fotográfica Leica DFC295. A nomenclatura morfológica está baseada em Terra (1995) exceto para a genitália masculina que segue a proposta de Cerdá (1993). Os exemplares foram depositados na Coleção Entomológica Professor Johann Becker do Museu de Zoologia da Universidade Estadual de Feira de Santana, Brasil (MZFS) e no Museu de Zoologia da Universidade de São Paulo, Brasil (MZSP).

Os espécimes foram coletados em duas áreas inseridas no bioma da Caatinga, uma localizada ao norte do estado da Bahia e outra no sul do estado de Piauí (Fig. 1). O bioma Caatinga possui um clima quente e semiárido, com forte sazonalidade de precipitação sempre inferior à $1.000 \mathrm{~mm}$ de chuva anuais distribuídas entre três a seis meses e elevada evapotranspiração de $1.500 \mathrm{~mm}$ a $2.000 \mathrm{~mm}$ anuais (Velloso et al. 2002).

$\mathrm{Na}$ Bahia, os espécimes foram coletados em um campo de dunas continentais $\left(10^{\circ} 07^{\prime} \mathrm{S}, 42^{\circ} 53^{\prime} \mathrm{O}\right)$ inativas do Médio Rio São Francisco no município de Pilão Arcado (Fig. 2). As dunas se estendem por uma área de aproximadamente $7.000 \mathrm{~km}^{2}$ com profundidades de até $60 \mathrm{~m}$ (Barreto et al. 2002). A vegetação é do tipo hiperxerófila sobre os depósi- 

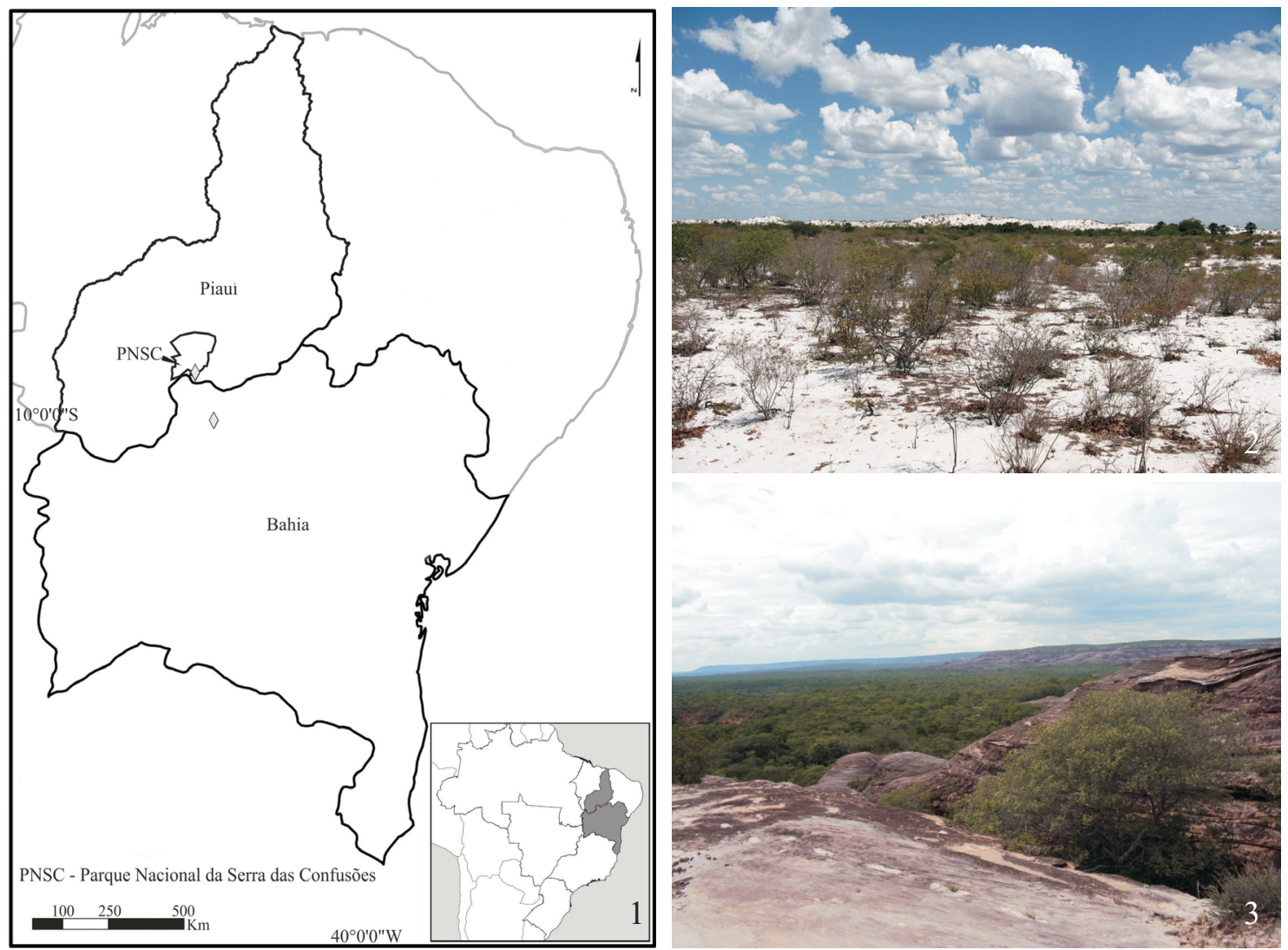

Figs. 1-3. 1. Mapa de distribuição de Orthoderella caatingaensis sp. nov.; 2. Dunas do Médio Rio São Francisco no município de Pilão Arcado, Bahia; 3. Parque Nacional da Serra das Confusões no município de Caracol, Piauí.

tos arenosos, com presença de plantas dos gêneros Pseudobombax, Maytenus e cactáceas como Pilocereus; a vegetação geralmente se apresenta agrupada em moitas, onde predomina a caatinga arbustiva (Barreto et al. 2002; Velloso et al. 2002).

No Piauí, as coletas foram realizadas no Parque Nacional da Serra das Confusões (PNSC), localizado no sudeste do estado, entre os municípios de Canto do Buriti, Caracol, Cristino Castro, Guaribas, Jurema, Tamboril do Piauí, e próximo à divisa norte do Estado da Bahia, com uma área de aproximadamente $5.024 \mathrm{~km}^{2}$ (DOU n ${ }^{\circ} 190 / 05$ de outubro de 1998). No parque as coletas foram realizadas na região conhecida como Fonte dos Bois $\left(09^{\circ} 13,228^{\prime} \mathrm{S}, 43^{\circ} 29,391^{\prime} \mathrm{O}\right)$, que são áreas mais baixas e de planícies arenosas, nas quais predomina diversas fisionomias de caatingas arbóreas (Fig. 3) (Bour \& Zaher 2005).

\section{TAXONOMIA}

Caracteres genéricos de Orthoderella Giglio-Tos, 1897

A nova espécie possui os seguintes caracteres diagnósticos do gênero, segundo a definição mais recente de Roy \& Stiewe (2011): cabeça pentagonal com vértice retilíneo mais elevado do que os olhos compostos, tubérculos justaoculares presentes e tão elevados quanto o vértice; escudo frontal transversal, pronoto liso com margens laterais paralelas e dilata- ção supracoxal pouco desenvolvida; metazona mais de $2,5 \mathrm{x}$ o comprimento da prozona; fêmures anteriores com 3 espinhos discoidais, 5 externos, 14 internos; tíbias anteriores possuindo entre 11-18 espinhos externos e entre 11-18 internos; macho com asas hialinas, desenvolvidas, ultrapassando o abdômen; cercos achatados na metade apical e pilosos; falômero dorsal direito com apódema anterior amplo e recoberto por fortes cerdas; falômero dorsal esquerdo com processo apical curvo de ápice arredondado e apófise falóide bem esclerotizada; falômero ventral com margem apical arredondada e um processo alongado para direita, terminando em uma membrana em forma de saco coberto por cerdas diminutas, em vista dorsal.

\section{Orthoderella caatingaensis sp. nov.}

Figs. 4-22

Material tipo. Holótipo macho: BRASIL, Bahia, Pilão Arcado, $10^{\circ} 07^{\prime} \mathrm{S}$, $42^{\circ} 53^{\prime} \mathrm{O}$, armadilha luminosa, 27.XI.2008, Menezes, E., Mota, E. \& Silva-Neto, A. col. (\#45.950) (MZFS); 1 parátipo macho, mesmos dados do holótipo (\#45.922) (MZFS); 2 parátipos machos, armadilha luminosa, $10^{\circ}$ 07'S, 42 53'O, 25.XI.2008, Menezes, E., Mota, E. \& Silva-Neto, A. col. (\#45.921 (MZSP), \#45.920 (MZFS); 1 parátipo macho, Piauí, Caracol, Serra das Confusões, Fonte dos Bois, 09²13,228'S, 43²9,391'O, 9-16.XII.2010, armadilha luminosa, França, D. \& Costa, A. cols., (\#51.608) (MZFS). Não foi observada variação de tamanho nas medidas dadas abaixo entre o holótipo e os parátipos machos estudados. 
Etimologia. O epíteto específico faz referência ao domínio brasileiro das caatingas onde os exemplares foram coletados.

Diagnose. Olhos compostos arredondados; coxas anteriores com mancha preta da face interna até a face externa posterior, apófise falóide do falômero dorsal esquerdo trapezoidal e margem direita sinuosa, processo anterior laminar projetado da apófise falóide, falômero ventral com processo distal esclerotizado e rugoso.

Descrição do macho. Coloração geral ocre (Fig. 5), forma do corpo delgada, comprimento corporal de $3,5 \mathrm{~cm}$ (distância do vértice até a ponta da placa subgenital). Cabeça (Fig. 4). Formato pentagonal; aproximadamente $0,73 \mathrm{x}$ mais longa do que larga; vértice com ápice retilíneo mais alto que a linha imaginária que une o topo dos olhos; tubérculos justaoculares tão altos quanto o ápice do vértice. Mandíbulas, em vista lateral, com ou sem mancha mediana ao longo do comprimento, variando de avermelhada a preta. Palpômero maxilar 4 com mancha preta ventral na metade basal do comprimento; palpômero maxilar $5 \mathrm{com}$ ou sem mancha preta ventral longitudinal em quase toda sua extensão. Olhos arredondados, pouco projetados lateralmente; ocelos desenvolvidos, elípticos. Escudo frontal alongado, 3,6x mais largo que alto com a margem superior mediana arqueada com faixa preta mediana transversal. Antenas ocre escuro, filiformes, com aproximadamente $2 \mathrm{x}$ o comprimento do pronoto. Escleritos cervicais: os dois pares dorsais com manchas pretas no ápice; o par lateral com uma faixa preta na borda inferior.

Tórax. Pronoto retangular em vista dorsal (Fig. 5), 3,7x mais longo que largo, 0,28x o comprimento corporal; margens laterais lisas com diminutas cerdas; com padrões de linhas pretas longitudinais; duas pequenas manchas pretas nas diminutas calosidades medianas na margem posterior. Prozona com margem anterior arredondada, margens laterais paralelas. Metazona com aproximadamente 2,7x o comprimento da prozona. Dilatação supracoxal pouco desenvolvida. Fissura transversal conspícua. Carena longitudinal e conspícua anteriormente evanescendo em direção à região posterior.

Pernas anteriores. Coxas alcançando a base do proesterno, com $0,6 \mathrm{x}$ o comprimento do pronoto; mancha preta recobrindo $0,6 \mathrm{x}$ o comprimento e metade da largura na face interna (Fig. 6) e metade do comprimento e da largura na face externa posterior (Fig. 7); margem da face dorsal anterior e da posterior das coxas, lisas com diminutas cerdas espaçadas. Trocânteres com duas pequenas manchas alongadas, uma superior na base da articulação com os fêmures, a outra, menos larga, na face ventro-lateral. Fêmures triangulares, com 0,8 x o comprimento do pronoto; face dorsal com linha preta variável no comprimento, podendo estar ausente ou na forma de manchas; face interna na base dos fêmures com três manchas internas, uma triangular junto à borda após a canaleta da garra tibial e as outras duas antes da canaleta da garra tibial, uma delas circular (que pode estar ausente) sobre a base da inserção do trocanter-fêrmur e a outra subretangular no final da inserção (Fig. 8); face ventral sem
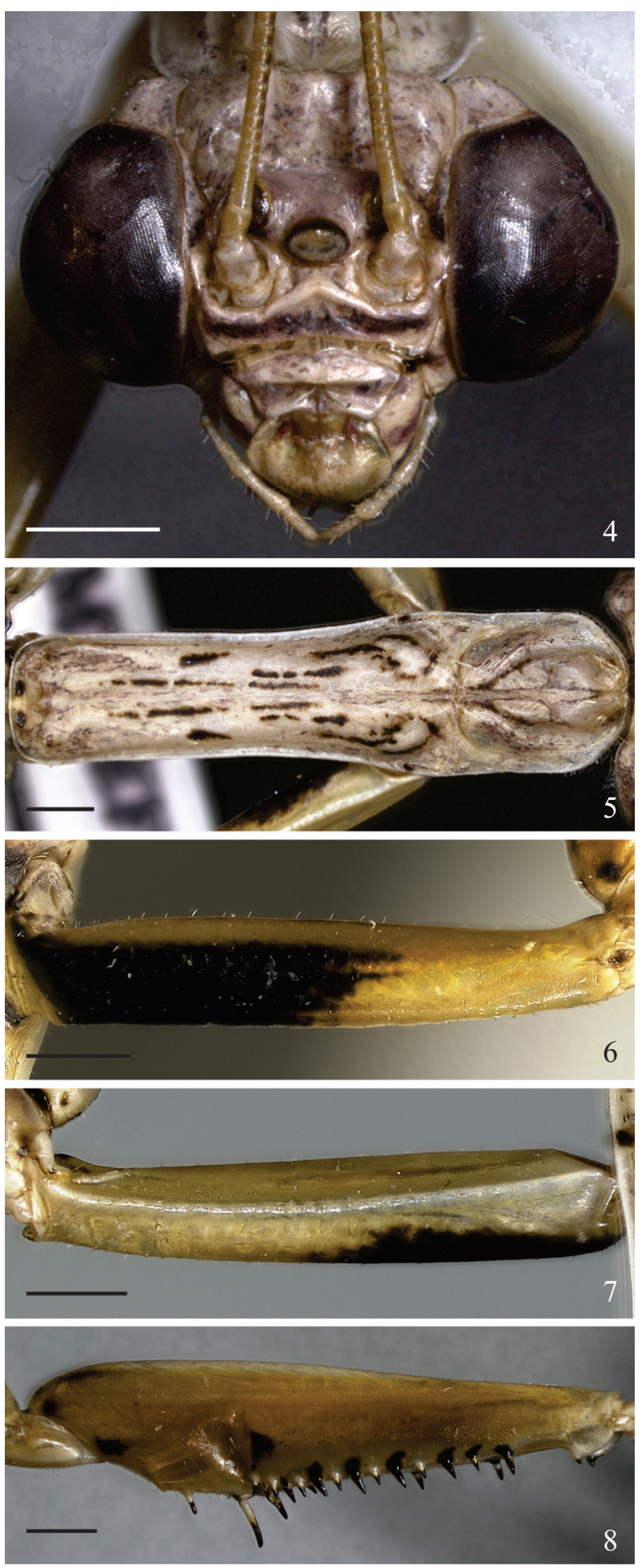

Figs. 4-8. 4,6-8. Holótipo: 4. Cabeça, vista anterior; 6. Coxa anterior esquerda, vista interna; 7. Coxa anterior esquerda, vista externa; 8. Fêmur anterior esquerdo, vista interna; 5. Parátipo \#45.920 pronoto, vista superior. Escalas $=1 \mathrm{~mm}$.

mancha preta; com cinco espinhos externos, sem contar o do lóbulo apical, pretos somente na ponta, circundados por um anel preto, o primeiro preto apenas na face ventral posterior, o segundo apenas na base da face externa (manchas podem 

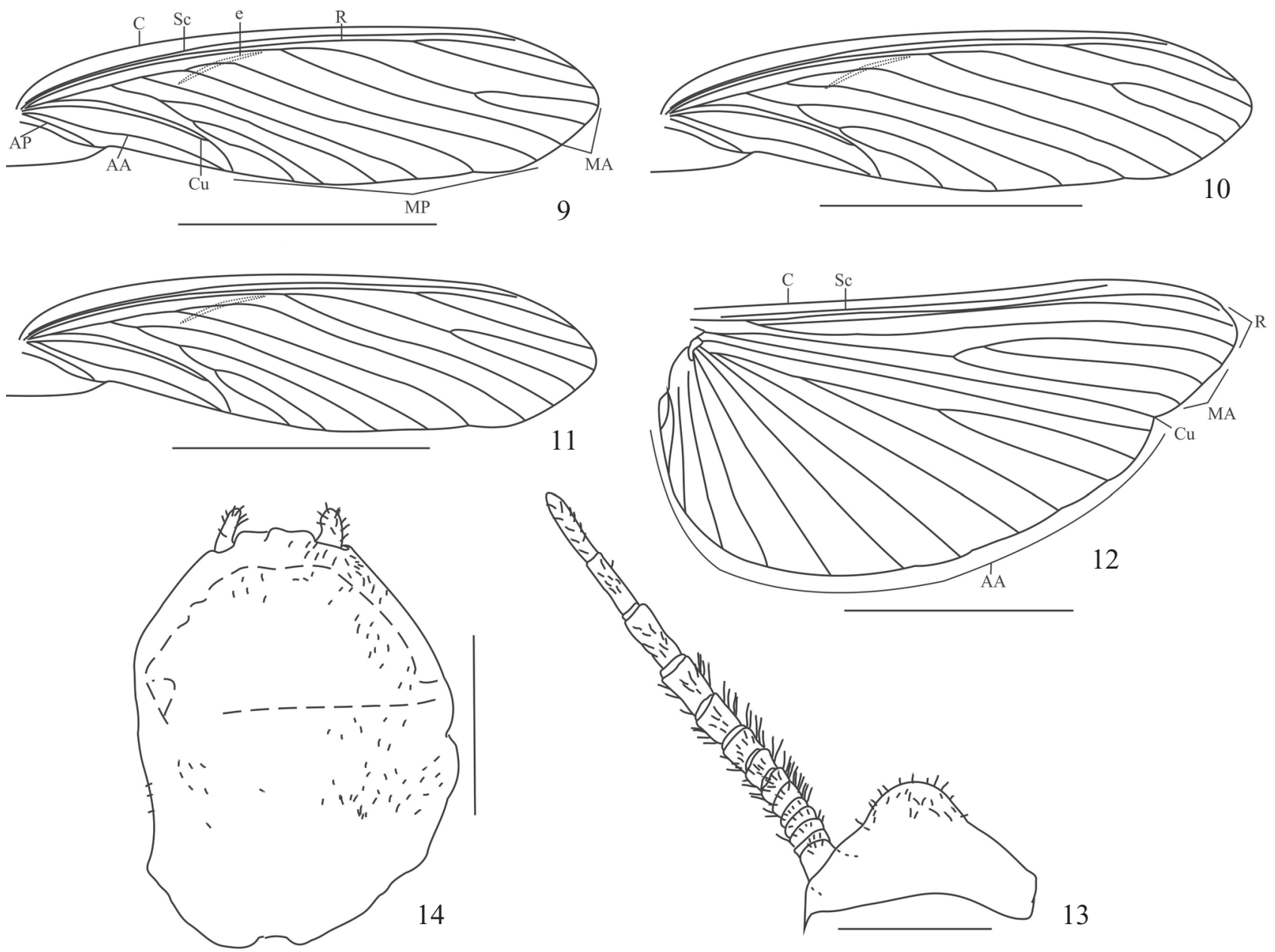

Figs. 9-14. 9-11. Tégminas. 9. Holótipo; 10. Parátipos \#45.920 e \#45.921; 11. Parátipo \#45.922; 12. Holótipo, asa; 13. Holótipo, placa supra-anal e cerco; 14. Holótipo, placa subgenital. Legenda: nervuras das tégminas e asas: AA. anal anterior, AP anal posterior, C costal, Cu cubital, e pteroestigma, MA medial anterior, MP medial posterior, $\mathrm{R}$ radial, $\mathrm{Sc}$ subcostal. Escalas $=1,0 \mathrm{~cm}$.

apresentar reduções); geralmente com 14-15 espinhos internos, sem contar o do lóbulo apical; série com dois espinhos pequenos e seis pares de espinhos pequeno-grande; todos os espinhos pequenos pretos somente na ponta; os espinhos grandes totalmente pretos e/ou escurecidos na face interna, com uma mancha preta na base na face interna (pode estar reduzida); o primeiro espinho grande com mancha preta menor na face interna; três espinhos discoidais femorais, o primeiro mais afastado dos restantes, o segundo com o dobro do comprimento do terceiro. Tíbias anteriores com metade do comprimento do pronoto (sem considerar a garra tibial apical), com mancha preta ventral iniciando após a projeção ventral basal e terminando na linha de início da série de espinhos tibiais internos; processo da inserção tíbio-tarsal preto; normalmente com 12 espinhos externos, podendo variar de 11 a 13; normalmente 17 espinhos tibiais internos, ocasionalmente 16; espinhos internos e externos pretos na ponta, último espinho tibial externo com uma mancha preta na base interna; garra tibial preta na ponta. Tarsos com $0,6 \mathrm{x}$ o comprimento do pronoto; tarsômero 1 tão longo quanto os restantes juntos, com fina linha preta ventral na metade basal, que pode estar ausente; tarsômeros 2-4 com faixa preta ventral, apical, que corre longitudinal na face externa.

Tégminas (asas mesotorácicas). Comprimento igual a 2,6x o comprimento do pronoto, em repouso ultrapassam o abdômen e não ultrapassam as asas metatorácicas; superfície hialina. Nervuras concolores à superfície da tégmina; vênulas transversais pretas; vênulas da área costal retilíneas e paralelas; radial (R) uniramificada; medial anterior (MA) biramificada; medial posterior (MP) pentaramificada (Fig. 9), podendo também se apresentar tetraramificada (Fig. 10) ou ainda pentaramificada em outra disposição (Fig. 11); anal anterior (AA) não ramificada (Fig. 9). Falsas nervuras longitudinais entre as nervuras verdadeiras. Estigma alongado concolor à superfície da tégmina.

Pernas medianas. Coxas com listra preta longitudinal na face ventral da margem externa, podendo também estar ausente. Fêmures $0,65 \mathrm{x}$ o comprimento do pronoto, pilosos e com faixa preta na face dorsal apical com cerca de $0,25 \mathrm{x}$ do comprimento deles; presença de mancha circular na face posterior apical (manchas podendo estar ausentes). Tíbias 0,57x o comprimento do pronoto, pilosas; presença de man- 

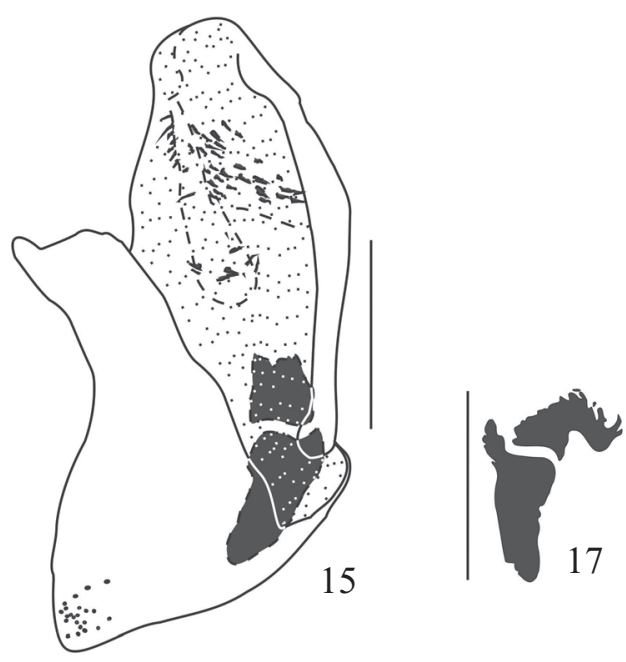

17
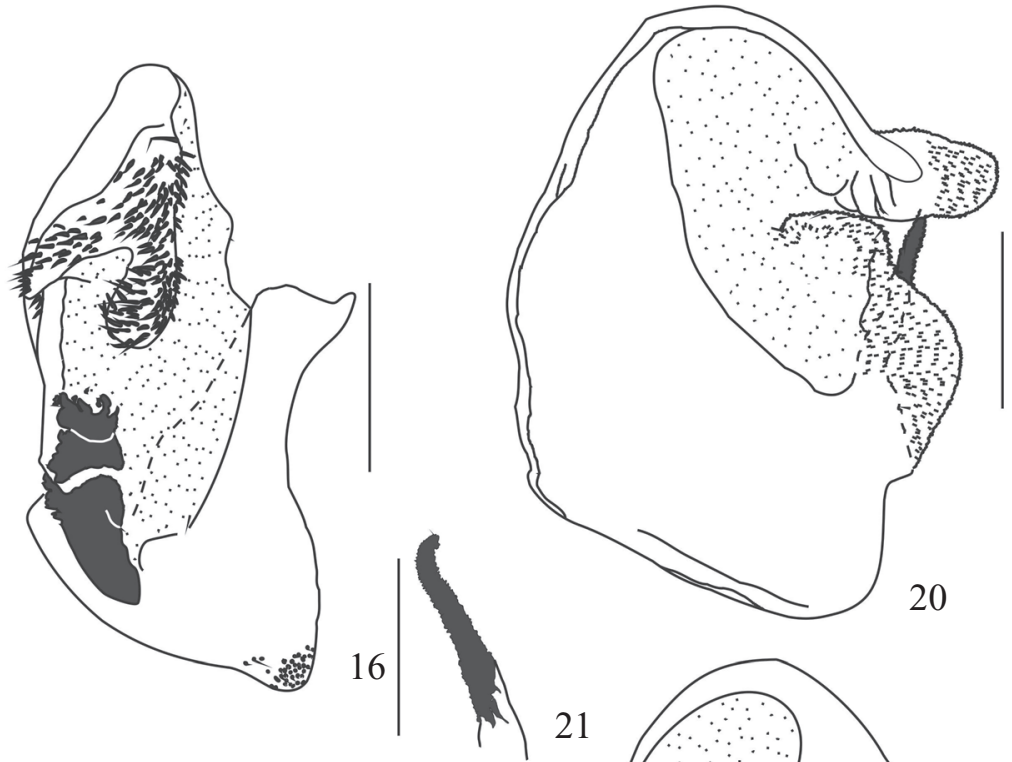

20

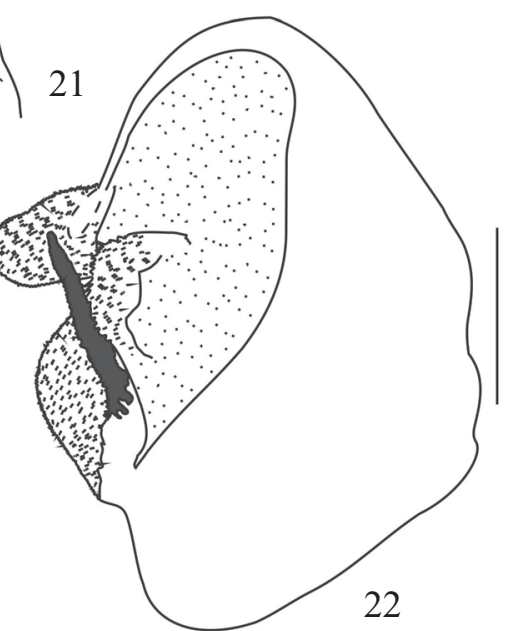

Figs. 15-22. 15-20, 22. Holótipo. 15. Falômero dorsal direito, vista dorsal; 16. Falômero dorsal direito, vista ventral, 17. Placa ventral e processo ventral em vista lateral; 18. Falômero dorsal esquerdo, vista dorsal; 19. Falômero dorsal esquerdo, vista ventral; 20. Falômero ventral, vista dorsal; 21. Parátipo \#45.922, processo distal, vista ventral; 22. Falômero ventral, vista ventral. Escalas $=0,5 \mathrm{~mm}$.

chas circulares pretas em série na face posterior; presença de linha preta na ponta apical. Tarsos com $0,5 \mathrm{x}$ o comprimento do pronoto; tarsômeros 1-5 com faixa preta longitudinal na face superior.

Asas metatorácicas. Comprimento igual a 2,5x o comprimento do pronoto; superfície hialina. Nervuras concolores à superfície da asa; vênulas da área costal hialinas, retilíneas e paralelas; radial biramificada; medial anterior biramificada; cubital sem ramificações; anal anterior com 13 ramos terminais; vênulas da área discoidal transversais pretas entre as nervuras subcostal, radial e medial anterior na ponta da asa (Fig. 12).

Pernas posteriores. Fêmures $0,8 \mathrm{x}$ o comprimento do pronoto, pilosos; padrão de coloração semelhante ao dos fêmures medianos. Tíbias 0,9x o comprimento do pronoto, pilosas; padrão de coloração semelhante às tíbias medianas. Tarsos com tamanho e coloração igual aos tarsos medianos.

Abdômen. Formato cilíndrico, 1,7x o comprimento do pronoto; tergitos abdominais com 1 par de manchas escuras de cada lado ou apenas os tergitos abdominais 2-4. Placa supra-anal triangular, 2x mais larga que longa; borda superior arredondada. Cercos curtos, aproximadamente $0,3 \mathrm{~cm}$; cilíndricos pouco achatados na metade apical, pilosos, com 14 artículos (Fig. 13). Esternitos com trios laterais de manchas circulares em diversas disposições ou com uma mancha circular preta em cada lado dos esternitos, e faixa mediana abdominal ventral ferrugínea. Placa subgenital elíptica, esparsamente pilosa. Estilos cilíndricos, pilosos, separados por um pequeno processo retangular (Fig. 14).

Complexo fálico. Falômero dorsal direito alongado. Braço médio longo; ápice truncado com uma ponta na margem externa (Fig. 15). Apódema anterior bifurcado, coberto com cerdas fortes (Fig. 16). Placa ventral esclerotizada, cônica, com projeção na base da face dorsal. Processo ventral esclerotizado, curvado para baixo (Fig. 17).

Falômero dorsal esquerdo. Formato triangular; lâmina dorsal com uma área dorsal membranosa e margem posterior arredondada com diminutos espinhos (Fig. 18); lâmina ventral triangular (Fig. 19). Processo apical cilíndrico, em forma de gancho, projetado sobre a lâmina dorsal para o lado 
esquerdo. Apófise falóide trapezoidal, esclerotizada; margens rugosas; margem direita distal levemente sinuosa. Processo anterior laminar, projetado da apófise falóide para esquerda, entre a lâmina ventral e dorsal.

Falômero ventral. Formato elíptico. Região medial anterior membranosa. Lóbulo médio com um processo arqueado para a direita, terminando em uma membrana em forma de saco, coberta na metade final por diminutas cerdas. Processo distal desenvolvido, bem esclerotizado, orientado diagonalmente para cima e direita (Fig. 20); retilíneo, mas curvado no ápice no parátipo \#45.922 (Fig. 21); com superfície rugosa (Fig. 22); encoberto por uma membrana com diminutas cerdas.

Fêmea desconhecida.

Orthoderella caatingaensis sp. nov. assemelha-se a $O$. brasiliensis quanto aos caracteres externos de coloração dos fêmures anteriores, apesar das possíveis variações cromáticas que podem ocorrer nas espécies deste gênero tal como foi apontado por Roy \& Stiewe (2011).

Quanto ao complexo fálico, a nova espécie apresenta o falômero dorsal direito semelhante ao de Orthoderella delucchii (Rivera 2003: Figs. 14, 15) na distribuição bifurcada e grande quantidade de espinhos ventrais e laterais do apódema anterior. Por outro lado, o falômero dorsal esquerdo, que apresenta uma apófise falóide trapezoidal esclerotizada, é semelhante ao de Orthoderella elongata. Entretanto, o braço médio do falômero dorsal direito da nova espécie é mais largo do que das outras espécies do gênero (Roy \& Stiewe 2011: Figs. 2, 6a,7a, 10a).

O falômero ventral com um processo distal desenvolvido e esclerotizado está presente na espécie nova e em Orthoderella delucchii (Roy \& Stiewe 2011: Fig. 7), no entanto com formato diferente. Este processo está ausente em Orthoderella ornata (Roy \& Stiewe 2011: Fig. 2), Orthoderella brasiliensis (Roy \& Stiewe 2011: Fig. 6) e Orthoderella elongata (Roy \& Stiewe 2011: Fig. 10).

A nova espécie diferencia-se das outras espécies de Orthoderella, pelas proporções corporais (ver chave). Assim sendo, $O$. caatingaensis sp. nov. representa a primeira espécie com registro para a região semiárida do nordeste brasileiro.

Chave para as espécies de Orthoderella Giglio-Tos [modificada de Roy \& Stiewe (2011)]

1a. Cabeça 1,15-1,3x mais longa do que larga; olhos elípticos alongados (mais de 2x mais longo do que largo); fêmures anteriores sem manchas pretas na face interna

O. elongata

1b. Cabeça tão longa quanto larga ou mais larga do que longa; olhos ovóides (igual ou menor que $2 \mathrm{x}$ mais longos do que largos) ou arredondados; fêmures anteriores com manchas pretas na face interna.

2a. Cabeça tão longa quanto larga .................................... 3

2b. Cabeça com comprimento menor que $0,9 \mathrm{x}$ a largura .. 4

3a. Fêmures anteriores com duas manchas pretas basais na face interna (às vezes uma mancha ausente); cercos maiores do que $7 \mathrm{~mm}$. O. brasiliensis 3b. Fêmures anteriores sem manchas pretas basais na face interna; cercos menores do que $7 \mathrm{~mm}$. O. ornata

4a. Comprimento corporal de $35 \mathrm{~mm}$; olhos arredondados; coxas anteriores com mancha preta da face interna até face externa posterior; fêmures anteriores com duas manchas pretas basais na face interna (às vezes a inferior ausente); canaleta do fêmur anterior com uma mancha preta anterior triangular; tíbias anteriores com 11-13 espinhos externos O. caatingaensis $\mathbf{s p . ~ n o v . ~}$

4b. Comprimento corporal de 42-51 mm; olhos ovóides; coxas anteriores sem mancha preta; fêmures anteriores normalmente sem manchas pretas basais na face interna; canaleta do fêmur anterior com uma mancha anterior circular (Rivera 2003: Fig. 9); tíbias anteriores com 16-18 espinhos externos.... O. delucchii

Key to species of Orthoderella Giglio-Tos [modified from Roy \& Stiewe (2011)]

1a. Head 1.15-1.3x longer than wide; eyes elongated and elliptical (more than $2 \mathrm{x}$ longer than wide); fore femora without black spots on inner face .................. O. elongata

1b. Head length equal or shorter than its width (in frontal view); eyes ovoid (equal to or less than $2 \mathrm{x}$ longer than wide) or rounded; fore femora with black spots on inner

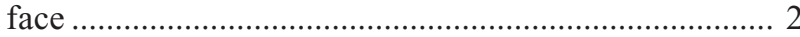

2a. Head as long as wide ................................................... 3 2b.Head length less than $0.9 x$ its width .......................... 4

3a.Fore femora with one or two basal black spots on inner face; cerci longer than $7 \mathrm{~mm}$.................. O. brasiliensis

3 b. Fore femora without basal black spots on inner face; cerci shorter than $7 \mathrm{~mm}$

O. ornata

4a. Body length $35 \mathrm{~mm}$; eyes rounded; fore coxae exhibiting a black, basal spot on its inner face that extends into the posterior, external face of the same; fore femora with one or two black spots on its inner face and another black, triangular spot right in front of the femoral groove; fore tibiae with 11-13 external spines

O. caatingaensis $\mathbf{s p . ~ n o v . ~}$

4b. Body length 42-51 mm; eyes ovoid; fore coxae without black spot; fore femora usually lacking black, basal spots on the inner face, although a black, circular spot is present right in front of the femoral groove (Rivera 2003: Fig. 9); fore tibiae with 16-18 external spines O. delucchii

\section{AGRADECIMENTOS}

Os autores agradecem ao Programa de Pesquisa em Biodiversidade do Semi-árido (PPBio/Semi-árido) e ao Projeto Cooperação e Consolidação de Pesquisas em Biologia, Ecologia, Conservação e Sistemática de Insetos Sociais (Hymenoptera) entre grupos de pesquisa em insetos sociais do Programa de Pós-Graduação em Zoologia-PPGZoo (UEFS) e PPGZoo (USP), pelo financiamento à pesquisa $\mathrm{e}$ coletas. ECM recebeu bolsa de Mestrado da CAPES. FB tem bolsa de pesquisa do CNPq (302120/2009-2). 


\section{REFERÊNCIAS}

Agudelo, A.A., Lombardo, F. \& Jantsch, L.J. 2007. Checklist of the Neotropical mantids (Insecta, Dictyoptera, Mantodea). Biota Colombiana 8: $105-158$.

Barreto, A.M.F., Suguio, K., Oliveira, P.E. \& Tatumi, S.H. 2002. Campo de Dunas Inativas do Médio Rio São Francisco, BA - Marcante registro de ambiente desértico do Quaternário brasileiro, p. 223-231. In: Schobbenhaus,C., Campos, D.A., Queiroz, E.T., Winge, M. \& BerbertBorn, M.L.C. (Eds.). Sítios Geológicos e Paleontológicos do Brasil. Comissão Brasileira de Sítios Geológicos e Paleobiológicos (SIGEP), Brasília. Disponível em: http://vsites.unb.br/ig/sigep/sitio056/ sitio056.pdf (acessado em 1 de fevereiro de 2011).

Bour, R. \& Zaher, H. 2005. A new species of Mesoclemmys, from the open formations of northeastern Brazil (Chelonii, Chelidae). Papéis Avulsos de Zoologia 45: 295-311.

BRASIL. Decreto ${ }^{\circ} 190$, de 5 de outubro de 1998. Cria o Parque Nacional da Serra das Confusões, nos Municípios de Caracol, Guaribas, Santa Luz e Cristino Castro, no Estado do Piauí, e dá outras providências. Diário Oficial [da República Federativa do Brasil], Brasília, ANO CXXXVI, p.1, 5 out. 1998. Seção 1.

Cerdá, F. 1993. Valor taxonómico del complejo fálico en mántidos neotro- picales (Dictyoptera: Mantodea). Boletín de Entomología Venezolana 8: $33-52$.

Cumming, J. 1992. Lactic Acid as an agent for macerating Diptera specimens. Fly times 8: 7 .

Giglio-Tos, E. 1897. Ortotteri. Viagio del Dott. A. Borelli nel Chaco boliviano e nella Republica Argentina. Bollettino dei Musei di Zoologia ed Anatomia Comparata della Reale Università di Torino 12: 1-47.

Rivera, J. 2003. Apuntes sobre algunas especies de Photininae de Perú, incluyendo la descripción de una nueva especie de Orthoderella GiglioTos, 1897 (Dyctyoptera: Mantodea: Mantidae). Revista Peruana de Entomología 43:7-12.

Rivera, J. 2010. A historical review of praying mantid taxonomy and systematics in the Neotropical Region: State of knowledge and recent advances (Insecta: Mantodea). Zootaxa 2638: 44-64.

Roy, R. \& Stiewe, M.B.D. 2011. Révision du genre néotropical Orthoderella Giglio-Tos, 1897 (Mantodea, Mantidae, Photinainae). Bulletin de la Société Entomologique de France 116: 43-56.

Terra, P.S. 1995. Revisão sistemática dos gêneros de louva-a-deus da região neotropical (Mantodea). Revista Brasileira de Entomologia 39:13-94.

Velloso, A.L., Sampaio, E.V.S.B. \& Pareyn, F.G.C. 2002. Ecorregiões Propostas para o Bioma Caatinga. Recife, Instituto de Conservação Ambiental The Nature Conservancy do Brasil, 76 p.

Received 05 April 2012; accepted 03 February 2013

Associate Editor: Daniela M. Takiya 